\title{
Aproximación a una tipología de los territorios en conflicto: el caso del Oriente de Caldas, Colombia*
}

Approach to a Typology of Territories in Conflict: The Case of East Caldas, Colombia

Aproximação a uma tipologia dos territórios em conflito: o caso do Oriente de Caldas, Colômbia

\author{
Diego Antonio Narváez Medina * \\ Jessica Tatiana Castaño Urdinola ${ }^{* \star *}$
}

Recibido: 6 de agosto de 2018

Aprobado: 28 de mayo de 2019

Doi: https://www.doi.org/10.12804/revistas.urosario.edu.co/territorios/a.705 1

Para citar este artículo:

Narváez Medina, D. A. \& Castaño Urdinola, J. T. (2020). Aproximación a una tipología de los territorios en conflicto: el caso del Oriente de Caldas, Colombia. Territorios (42), 1-23. Doi: https://www.doi. org/10.12804/revistas.urosario.edu.co/territorios/a.7051

* Este artículo de investi-
gación se deriva del pro-
ceso de investigación de la
tesis doctoral titulada "Las
transformaciones territo-
riales de los órdenes socioes-
paciales locales derivadas
del conflicto social en el
Oriente de Caldas (1989-
2018)", adelantada por
Diego Antonio Narváez
Medina, en el marco del
Doctorado en Estudios
Territoriales; y de la
Investigación financiada
por la Vicerrectoria de
Investigacionesy Posgrados
de la Universidad de
Caldas y apoyada por el
Programa de Desarrollo
para la Paz del Magdalena
Centro, titulada "El con-
flicto como factor de trans-
formación territorial en
el Oriente de Caldas: un
aporte al fortalecimiento 
Palabras clave

Tipología,

conflicto, territorio, multiterritorialidad, espacio.

Keywords

Tipology, conflict, territory, multiterritoriality, space.

Palavras-chave

Tipologia,

conflito, território, multiterritorialidade, espaço.

territarias 42

\section{RESUMEN}

Este artículo se construye a partir del proceso de investigación titulado "El conflicto como factor de transformación territorial en el Oriente de Caldas: un aporte al fortalecimiento de los vínculos de cooperación y de confianza institucional", ejecutado en ocho municipios del departamento de Caldas, Colombia. En estos territorios han aflorado distintas expresiones del conflicto que han evidenciado las contradicciones que se dieron por el territorio y en el territorio. El objetivo de esta investigación es mostrar, de una parte, la importancia metodológica de las tipologías como instrumento para ordenar la realidad y, por otra parte, avanzar en la construcción teórica sobre la multiterritorialidad, derivada del proceso de transformación territorial que se ha dado en la región. Haciendo uso de las categorías tipo como recurso metodológico, se concluye que el conflicto social, entendido como una categoría relacional, potencia cambios socioespaciales a partir de las contradicciones que se producen entre distintos actores individuales o colectivos.

\section{ABSTRACT}

This article is based on the research process entitled Conflict as a factor of territorial transformation in the East of Caldas: a contribution to strengthening the bonds of cooperation and institutional trust, executed in eight municipalities of the Department of Caldas, Colombia. Different expressions of conflict emerged that evidence the contradictions occurred for and in the territory. As an objective, we propose to show, on the one hand, the methodological importance of the typologies as an instrument to order reality, and on the other hand, to advance in the theoretical construction on the multi-territoriality, derived from the process of territorial transformation that has taken place in the region. Using type categories as a methodological resource, the research allowed to conclude that social conflict, understood as a relational category, promotes socio-spatial changes based on the contradictions that occur between the different individual or collective actors.

\section{RESUMO}

Este artigo se constrói a partir do processo de pesquisa titulado "O conflito como fator de transformação territorial no Oriente de Caldas: um aporte ao fortalecimento dos vínculos de cooperação e de confiança institucional”, executado em oito municípios do Departamento de Caldas, Colômbia. Nestes territórios têm surgido distintas expressões do conflito que têm evidenciado as contradições que se deram pelo território e no território. Como objetivo nos propomos mostrar, por um lado, a importância metodológica das tipologias como instrumento para ordenar a realidade e, por outra, avançar na construção teórica sobre a multiterritorialidade, derivada do processo de transformação territorial que se tem dado na região. Fazendo uso das categorias tipo como recurso metodológico, se conclui que o conflito social, entendido como uma categoria relacional, potência mudanças socioespaciais a partir das contradições que se produzem entre diferentes atores individuais ou coletivos. 


\section{Introducción}

Se asume el conflicto social como una noción categóricamente relacional, que se expresa en el acto dialéctico de la controversia, en el desacuerdo entre dos seres humanos o más, o entre dos grupos o más, y la lucha que implica llegar a puntos de acuerdo y establecer consensos. Como proceso dialéctico, no tiene que ser visto como algo negativo - que fue la mirada dominante sobre este fenómeno hasta hace poco tiempo-, sino como un factor de cambio y creatividad; la historia ha demostrado que si no se diseñan estrategias para gestionar los conflictos y no se buscan salidas concertadas, la pugnacidad entre los sectores en conflicto de una sociedad pueden pasar a la violencia, a veces armada, con el costo social marcado por el dolor y la miseria que trae consigo.

En la producción del territorio, las interacciones humanas son una constante y en ellas afloran los conflictos, presentándose fenómenos de territorialización/ desterritorialización. Esto se pudo evidenciar en el trabajo de campo realizado en la investigación base del presente artículo, que se centró en la búsqueda de las conexiones lógicas entre el conflicto y la transformación territorial y su materialización en la vida cotidiana de los pobladores del Oriente de Caldas ${ }^{1}$. En el presente documento se presenta el fruto de las reflexiones de esta investigación, dirigidas a la construcción de una tipología de territorios en conflicto, partiendo del presupuesto de que las clasificaciones son útiles para pensar y ordenar la realidad, más no son camisas de fuerza que impidan hibridaciones e intersecciones entre categorías.

Para ubicar al lector en el escenario de los hechos, es necesario mencionar que el departamento de Caldas se encuentra en el centro occidente de Colombia, y el Oriente de Caldas se ubica en la vertiente oriental de la cordillera central (ver figura 1); su geografía se extiende desde la divisoria de aguas de la cordillera central, a los 3200 m.s.n.m., en el municipio de Marulanda y baja hasta los 176 m.s.n.m., a orillas del río Magdalena, en el municipio de La Dorada. Su geografía vertical le proporciona los tres pisos térmicos, en donde se pueden producir una gran variedad de productos agrícolas, pecuarios y forestales. La energía del relieve, y la presencia de reservas naturales como la Selva de Florencia y la Laguna de San Diego, hacen que esta región se caracterice por su biodiversidad y gran riqueza hídrica, esta última aprovechada para la producción de energía eléctrica.

Esta región se configuró territorialmente como producto de la acción de dos dinámicas históricas, económicas, socio-culturales y ambientales claramente diferenciadas: de un lado, el Oriente Montañoso, apropiado y transformado por la acción de los colonos antioqueños, tales como Marulanda, Pensilvania, Marquetalia y Samaná, los cuales tienen la mayor parte de su superficie ubicada en el denominado 'cinturón cafetero', de los vínculos de cooperación $y$ de confianza institucional", en la que participaron los dos autores del presente articulo.

** Profesor, Universidad de Caldas, Colombia. Correo electrónico: diego. narvaez_m@ucaldas.edu. co. ORCID: http://orcid. org/0000-0001-6999-7310

* * * Profesora, Universidad de Caldas, adscrita al Departamento de Desarrollo Humano, Caldas, Colombia. Correo electrónico: jessica. castano@ucaldas.edu. co. ORCID: http://orcid. org/0000-0001-7343-1483

${ }^{1}$ Los municipios en los que se llevó a cabo el trabajo de campo fueron: La Dorada, Samaná, Victoria, Norcasia, Manzanares, Marquetalia, Pensilvania y Marulanda.

territarias 42

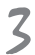


a una altura sobre el nivel del mar que oscila entre los 1000 y 2000 m.s.n.m.; su economía se deriva fundamentalmente de la caficultura, en menor cuantía de la caña panelera y frutales como el aguacate.

Más al oriente, y también de herencia antioqueña, se encuentran Victoria y Norcasia, que se podrían denominar como municipios de transición, pues parte de sus tierras están en la montaña y parte en el valle, producen también café, pero su fortaleza económica radica en la ganadería y en productos sustitutivos del café como el caucho y el cacao. Finalmente, está La Dorada, ubicada a 176 m.s.n.m., producto de un poblamiento de la tierra caliente de fines del siglo XIX y las dos primeras décadas del XX. El asentamiento se dio asociado con el tráfico fluvial por el río Magdalena, su economía es la más diversificada de la región, cuenta con ganadería, pesca, minería y ha desarrollado el comercio y el sector

Figura 1. Mapa del Oriente de Caldas

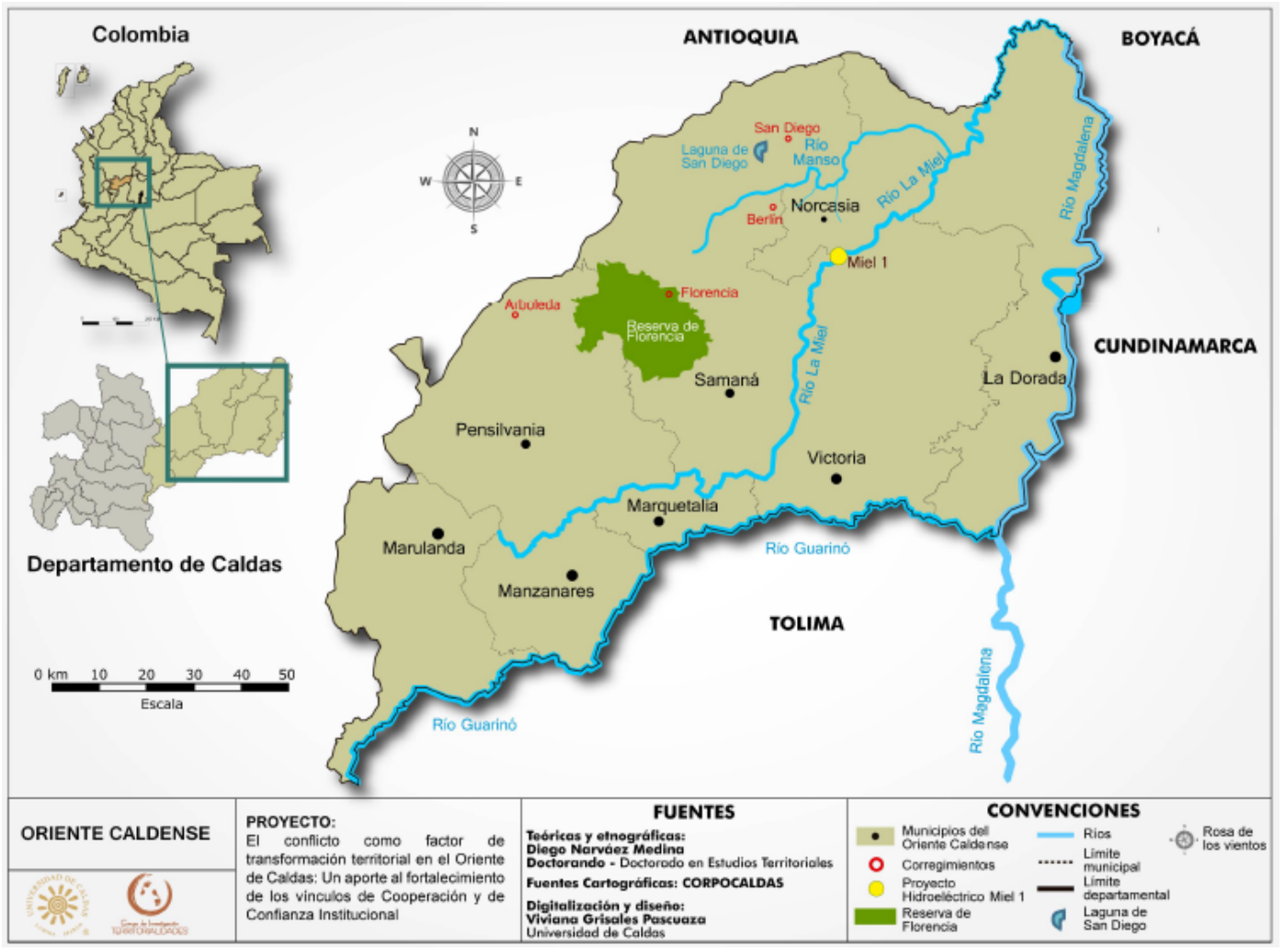

Fuente: elaboración propia. 
turístico; por su funcionalidad económica y ubicación espacial estratégica, se constituyó en el centro regional del Oriente.

De lo anterior, se puede deducir que el Oriente de Caldas es una región históricamente ensamblada, aunque presenta una tensión constante: de una parte, sus diferencias morfológicas, económicas y socioculturales tienden a fragmentar la montaña del valle, y de la otra, las relaciones de vecindad, sus dinámicas poblacionales e intercambios económicos y poderes políticos locales y regionales, tienden a integrarlas. Parafraseando a Massey (2008), esta región tiene que ser conceptualizada, no como una simple diversidad, sino como una región de encuentro de trayectorias potencialmente conflictivas, constituida por geometrías complejas de poder diferenciado.

\section{Metodología}

En las ciencias sociales, desde sus orígenes, se construyeron clasificaciones, como una forma inicial de diferenciar los fenómenos sociales. Así, se recurre a la clasificación como un primer nivel de interpretación y abstracción de la realidad, y en un segundo momento se acude a la categorización, para condensar las múltiples determinaciones del fenómeno en un concepto que impulse la construcción teórica de la realidad.

Si bien hubo muchas formas de categorizar y clasificar aspectos de la realidad social, fue Max Weber (2002) quien propuso la noción de tipología, utilizada como estrategia teórica y metodológica en sus estudios sobre las formas de dominación legítima, clasificándolas en tres categorías con sus respectivos atributos: 1) la racional, 2) la tradicional, y 3 ) la carismática. En cuanto son construcciones teóricas, Weber las denominó 'tipos ideales o puros', de ahí que en adelante a los intentos de clasificar mediante categorías se les ha dado el nombre genérico de tipología, o sea, formas tipo de abstracción de la realidad. Es conveniente señalar que el mismo Weber (2002) hace la salvedad de que ninguno de los 'tipos ideales' se encuentran en estado puro en la realidad, puesto que esta "es mucho más fluida que la teoría, y la utilidad de una clasificación solo puede demostrarla el efecto sistemático que con ella se busca" (pp. 172-173).

De otra parte, Nates (2011) al respecto dice que las categorías y las clasificaciones, al asumirlas como concepto, no son una distinción de valor sino una diferenciación práctica que permite ver mejor las cosas. En palabras de Nates:

La categoría concebida como la condición, la clase, la calidad y la cualidad de una cosa y la clasificación como su codificación, sistematización, ordenamiento, programación y tipificación, nos permite pensar de un mismo modo práctico la naturaleza (categoría) y la simbolización (clasificación) de las cosas, estén éstas representadas en objetos, hechos o discursos. Es por ello que categorizar, es territarias 42 
decir, hablar de la condición o cualidad de una cosa, y clasificar, es decir, referirse a su ordenamiento o sistematización, es ante todo un ejercicio territorializado (pp. 3-5).

El interés por el territorio que se evidencia en estos resultados de investigación radica en cuatro postulados: 1) el territorio es el espacio apropiado y valorizado simbólica y materialmente por los grupos humanos (Raffestin, 2011);2) el territorio no es neutro, no existe un territorio en sí, sino que existe en cuanto tiene significado para alguien (Lefebvre, 2013; Nates, $2011 \mathrm{~b}$ ); 3) Cualquier práctica espacial inducida por un sistema de acciones o de comportamientos, incluso embrionaria, se traduce en una "producción territorial"; y 4 ) ninguna sociedad, por elemental que sea, escapa a la necesidad de organizar el campo operatorio de su acción (Raffestin, 2011). Por lo tanto, en la realidad socialmente construida no se encuentra un territorio, sino múltiples territorios producto de las diversas formas de relacionarse de los individuos y los grupos humanos con el espacio (Haesbaert, 2011; Monnet, 1999). En el caso de esta investigación, las tipologías se construyeron como resultado de la producción del territorio, mediada por las acciones territorializantes de los distintos grupos armados, las decisiones tomadas por la Federación Nacional de Cafeteros y las que tomaron los inversores para la construcción de la represa hidroeléctrica La Miel. Dicho en términos

\section{territarias 42} de Monnet (1999):
[...] el espacio es territorializado por un actor geográfico, por su acción en/sobre el espacio; o sea, el territorio es un producto, y en tanto tal, es posible entender el territorio como un espacio producido en ciertas condiciones, para ciertos fines, por ciertos actores, con las cuales un grupo se apropia, delimita y transforma el espacio (pp. 1-2).

Derivado de lo anterior, la multiterritorialidad es un resultado esperado de las acciones territorializantes de los distintos agentes que interactúan en el espacio social; así, no es permitido considerar al territorio como una unidad homogénea, hacerlo es ignorar la conflictividad inherente a toda relación socioespacial (Mançano, 2013). Ante la diversidad de territorios percibidos en la zona de trabajo de campo, se intenta proponer una tipología de territorios en conflicto, partiendo del reto evidente que presenta el país en el tiempo que vive, donde se piensa en la construcción de paz desde los distintos territorios, lo que requiere de una comprensión inicial profunda de los conflictos que allí se han desarrollado.

Para llegar a la tipología que va a exponerse a continuación, se siguió este procedimiento: el proceso investigativo se enmarcó en el enfoque cualitativo de tipo comprensivo. Se utilizaron estrategias de investigación como la entrevista semiestructurada, la cartografía, el taller y el grupo focal. Se realizaron 39 entrevistas y 3 grupos focales de diferentes actores sociales e institucionales. Las entrevistas 
fueron dirigidas a mujeres y hombres víctimas del conflicto, dirigentes gremiales, funcionarios públicos locales y regionales, pescadores, jóvenes, afrodescendientes, líderes religiosos y líderes de organizaciones sociales de la región. Además, se utilizó el diario de campo, para lo cual se aplicó la observación directa e indirecta con el fin de conocer el territorio. Se sistematizó y analizó la información con ayuda del software ATLAS.ti.

Antes de continuar, es conveniente señalar que se asume el conflicto social como un factor de cambio y transformación de toda sociedad, como una encrucijada que debe ser resuelta con el concurso de los diferentes actores y de la creatividad y carácter democrático que tenga la salida al conflicto, la sociedad involucrada avanzará o se enredará en su búsqueda, como ha acontecido con los conflictos en Irak, Siria, la zona de Palestina, etc. Al respecto, Simmel (2010) dice que el conflicto social es un factor integrador, una forma de socialización sin la que las sociedades no pervivirían. En este mismo sentido, Luhmann (1995) considera que, incluso en la cooperación, el conflicto se encuentra subyacente como mecanismo regulador que permite establecer las condiciones sobre las cuales esta puede edificarse y mantenerse.

En conclusión, se puede decir que la producción del territorio está cargada de conflictividad y de posibilidades de cambio, así que, en este caso, el conflicto armado y la crisis cafetera como formas de expresión del conflicto social han transformado las relaciones socioespaciales de los pobladores del Oriente de Caldas, configurando diferentes tipos de territorio; más aún, cuando se entiende por conflicto social aquella relación social que está presente en todo grupo humano, y todo grupo humano hace parte de un territorio.

\section{Resultados y discusión}

En aras de ubicar al lector, se presentará un bosquejo de lo que ha sido el conflicto armado en la región de estudio, en la que se observa la gran capacidad de transformación territorial del conflicto; las palabras se quedan cortas para expresar los resultados de la barbarie contra personas inocentes e inermes que, sin estar enlistadas en ningún bando, se convirtieron en blanco de los diferentes grupos armados legales e ilegales.

Franco (2009) muestra que hay una serie de elementos subjetivos que mueven a los actores del conflicto, y que no se pueden reducir a motivaciones restrictivas como la seguridad y el odio o enmarcar el sentido de su accionar en la dualidad entre agravio-codicia. La autora dice que "este tipo de conflicto, no es entonces, nada diferente a la interacción entre distintos actores, motivaciones e intereses bajo un contexto histórico y espacial determinado" (p. 87). La autora retoma uno de los planteamientos de Stathis Kalyvas, que resulta ilustrador para la argumentación de esta investigación: 
${ }^{2}$ El exterminio sistemático perpetrado por grupos paramilitares, por narcotraficantes y por fuerzas del Estado incluyó dos candidatos presidenciales -los abogados Jaime Pardo Lealy Bernardo Jaramillo Ossa-, 8 congresistas, 13 diputados, 70 concejales, 11 alcaldes, y se calcula en cinco mil los militantes asesinados; sin contar los cientos de exiliados (Grupo de Memoria Histórica, 2013).

${ }^{3}$ Llama la atención que Norcasia se constituyó como municipio en 1999, año en el que inició la construcción de la Hidroeléctrica.

\section{territarias 42}

[...] las guerras civiles no son conflictos binarios sino procesos complejos y ambiguos que fomentan una aparente mezcla masiva, aunque variable de identidades y acciones, al punto de ser definida por esta mezcla. Dicho de otra forma, la ambigüedad ampliamente observada es fundamental más que incidental a las guerras civiles; un asunto de estructura más que de ruido (Kalyvas, 2004, p. 51).

Frente a la ambigüedad presente en el conflicto, se puede decir que en el Oriente hubo dos momentos de configuración del conflicto armado: el primero en la década del setenta, que tiene como escenario la parte baja de la región, el valle del Magdalena, cuando se generaron los procesos de organización de las Autodefensas Campesinas del Magdalena Medio, inicialmente con el propósito de poner fin a las extorciones y los secuestros de las Farc a los propietarios de la zona. Su objetivo inicial tuvo un giro a partir de 1984, cuando su modus operandi cambió y los cuerpos caídos en combate no eran dejados en el lugar de su muerte, sino que eran descuartizados y tirados al río Magdalena. Además, sus prácticas de exterminio se dirigieron contra ladrones, trabajadoras sexuales, expendedores de droga y contra aquellas personas que les parecían incómodas, en otros términos, pusieron en ejecución la mal llamada 'limpieza social'.

Luego, con la complicidad de los altos mandos militares del batallón Bárbula, el apoyo de muchos de los ganaderos de la zona y las alianzas que hicieron con los narcotraficantes del Cartel de Medellín, se fortalecieron, convirtiéndose en un ejército irregular narco-paramilitar, lo que les sirvió para imponer un orden socioespacial de facto en todo el valle del Magdalena Medio. Uno de sus objetivos militares fueron los militantes de izquierda, con lo cual, las fuerzas paramilitares, en connivencia con las del Estado, fueron las responsables del aniquilamiento sistemático de sindicalistas, defensores / as de Derechos Humanos y de las y los militantes del partido Unión Patriótica. ${ }^{2}$

El segundo momento de incursión de los actores armados fue en 1999, cuando los frentes 9 y 47 de las Farc llegaron al Oriente Montañoso, procedentes del sur de Antioquia, específicamente a los corregimientos de Florencia, San Diego y Encimadas, del municipio de Samaná, y al corregimiento de Arboleda, en el municipio de Pensilvania, con la clara intención de tomar control del territorio. En ese momento, los paramilitares ya se habían fortalecido en el valle y subieron a la montaña, inicialmente al municipio de Norcasia, ${ }^{3}$ en donde contaron con la colaboración de la fuerza pública y la administración municipal. Su intención principal era contener a las Farc y proteger el proceso de construcción del embalse del Proyecto Hidroeléctrico Miel I, que se ubica en ese municipio, y que era un objetivo claro de la guerrilla por la importancia geográfica, económica y política del proyecto. 
Con base en los anteriores presupuestos, se ponen a consideración cinco tipos de territorios en conflicto que se han clasificado como: 1) territorios en conflicto armado, 2) en conflicto político, 3 ) en conflicto económico, 4) en conflicto ambiental y 5 ) en conflicto cultural. Además, es necesario marcar dos salvedades: por un lado, los territorios propuestos no se pueden encontrar en la realidad en estado puro, sino que cada uno de ellos puede tener matices de los otros, por ejemplo, el territorio en conflicto armado, en ciertos momentos y situaciones, puede tener connotaciones de carácter político, o de carácter económico, como cuando se dio el auge del cultivo de la coca. Por otro lado, estas tipologías deben siempre pensarse y comprenderse situadamente, en contexto, y no ser vistas como una generalización aplicable a todo espacio y en todo tiempo, sin pasar por el filtro de la particularidad del caso que se analice.

\section{Territorios en conflicto armado: control y delimitación implícita, por el miedo, el río, la quebrada, la cuchilla}

Se asumen los territorios en conflicto armado como aquellos en los que se libra una disputa entre dos o más grupos legales o ilegales para controlar el territorio, apropiarse de bienes de los pobladores y de los recursos del Estado, en concertación con políticos locales y regionales, que incluso tienen la pretensión de realizar un cambio en el orden socio-jurídico vigente, haciendo un uso sistemático de la violencia armada para lograr sus fines.

Hasta los primeros años de la década del ochenta, uno de los rasgos del modus operandi propio de la guerrilla, y que la diferenciaba de cualquier otro grupo armado ilegal, era que no asesinaban a los pobladores de las zonas en las que operaban, por el contrario, intentaban atraerlos por medio de la propaganda ideológica de cambio social. La escalada del conflicto hizo que los límites se fueran perdiendo y la sevicia y la barbarie cruzaron el límite, y en el Oriente de Caldas se encontraron pocas diferencias entre la forma de actuar de la guerrilla y la de los paramilitares. Los secuestros, las minas antipersona y el daño a la infraestructura eran exclusividad de la guerrilla, pero tanto los unos como los otros tenían en su inventario, como prácticas de guerra, las desapariciones, los asesinatos, los desplazamientos forzados, el cobro de vacunas y las masacres. Los paramilitares asesinaban, pero antes torturaban para sacar información, castigaban en público a quienes les desobedecían y ejercían un control más fuerte de la vida cotidiana de los pobladores.

Una de las transformaciones más notables que ocasionó el conflicto armado en la región, fue el abandono del campo. Con la llegada de los grupos armados, el espacio productivo se deprimió debido al abandono de la región de la mayoría de grandes comerciantes, quienes se encargaban de proveer los insumos para las labores 
${ }^{4}$ El boleteo era una práctica que consistia en enviarle un papel o boleta a una persona para que abandonara el pueblo, muchas veces, en la misma boleta se le ofrecía un irrisorio precio por la compra de sus propiedades. Fue una práctica que apareció en la llamada Violencia Politica (entre liberales y conservadores) de los años cuarenta y cincuenta del siglo pasado, cuya inadecuada resolución condujo al encadenamiento con el conflicto armado actual.

${ }^{5}$ En noviembre de 1999, el Frente 47 se tomó el corregimiento de Florencia; en diciembre de 2001, el $90 \%$ de la población se desplazó del corregimiento de San Diego; en julio del 2000, el frente 47 de las Farc se tomó el corregimiento de Arboleda, Pensilvania; en 2001 se dio el desplazamiento del corregimiento Encimadas, Samaná; en enero de 2002, se presentó la destrucción total de la vereda el congal del corregimiento de Florencia, Samaná y su consecuente desplazamiento (Cfr. Rutas del conflicto del CNMH y diario La Patria).

\section{territarios 42}

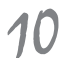

agropecuarias. Unos fueron asesinados, otros secuestrados, algunos extorsionados y todos 'boleteados', ${ }^{4}$ lo que generó destierros que más tarde se acentuarían con la retoma del territorio por parte de las fuerzas del Estado. La concentración de la tierra en pocas manos aparece como una de las grandes transformaciones territoriales generadas por el conflicto armado, con un índice de Gini que fluctúa entre 0.819 y 0.958 (IGAC, 2012), debido a que muchos terratenientes aprovecharon la situación para adquirir tierras a muy bajos costos, especialmente en el valle del Magdalena, en donde se presentan los niveles más altos de concentración.

Muchos pobladores del Oriente de Caldas expresaron que hasta cierto punto los grupos armados ilegales fueron útiles para mantener el orden social, pues controlaban el robo, las riñas callejeras y el consumo de drogas, entre otras situaciones consideradas indeseadas. De las entrevistas realizadas en la región, paradójicamente, se puede deducir que muchos habitantes de los municipios ven con buenos ojos la "limpieza social", llevada a cabo por los grupos paramilitares.

Los cuerpos fueron también territorios en disputa en medio del conflicto armado, y eran especialmente los hombres los llamados a defender los intereses de la patria o de los grupos armados ilegales. Los métodos de inducción son los mismos, las consecuencias igual de violentas, solo que cuando quien convoca es el Estado, esta acción se legitima porque defiende la soberanía nacional. En últimas, los pobladores del Oriente de Caldas jugaron dos roles igualmente trágicos: ser víctimas de la violencia y, además, tomar las armas para exterminar a los grupos armados ilegales de sus territorios, muchos de los cuales eran jóvenes de sus mismos pueblos.

Entre 1999 y 2002 se presenta el pico más fuerte de la violencia armada en el Oriente de Caldas, y la guerrilla y los paramilitares comenzaron a cooptar las organizaciones de base con miras a satisfacer sus intereses. Esto generó que muchos líderes comunitarios fueran asesinados por estar supuestamente aliados con uno u otro grupo. Las masacres, desplazamientos, falsos positivos y homicidios ${ }^{5}$ aumentaron dramáticamente durante este periodo, así como el miedo hacia cualquier grupo armado que portara un uniforme (legal o ilegal), a diferencia de los años anteriores donde algunas personas incluso legitimaban el actuar de algunos grupos ilegales.

El conflicto armado marca la experiencia cotidiana de los pobladores de un territorio. En el caso del Oriente de Caldas, las huellas físicas y psicológicas que dejó la violencia fueron tan fuertes, que en las narrativas las personas expresan un antes y un después del conflicto, lo que quiere decir que la historia personal, familiar y comunitaria se parte en dos con estos acontecimientos. Aún se dan algunos esfuerzos por realizar intervenciones psicosociales que permitan afrontar de forma más adecuada estos procesos. 
Las lealtades al territorio nacen del grado de territorialidad, y en un mismo espacio se pueden yuxtaponer varias lealtades a distintos actores territoriales (Montañez \& Delgado, 1998), como se pudo constatar en varios pueblos del Oriente, convertidos en corredores de tránsito de los grupos armados, donde se vieron obligados a convivir con unos y otros, de acuerdo con la dinámica impuesta por la disputa territorial. Dos de estos territorios fueron Berlín y San Diego, en Samaná, donde a ciertas horas hacía presencia la guerrilla, y en la otra parte del día circulaban los paramilitares.

En el territorio del conflicto armado, los actores armados marcaban fronteras territoriales, que variaban según la dinámica de la guerra, así que nunca fueron un dato fijo, sino, por el contrario, una demarcación inacabada e inestable constantemente en disputa, que contiene una pluralidad de límites en los que convergen diferentes ordenamientos y significados (Grimson, 2003). Usualmente, se hablaba de la guerrilla como 'los de arriba', y los paramilitares como 'los de abajo', lo que transformó las dinámicas políticas, comerciales y sociales de los pobladores, pues ya no se podía circular libremente por las vías de comunicación, ni por las trochas de uso habitual de los campesinos. Los ríos se convirtieron en un depósito de cuerpos, impactando el simbolismo de ocio y de unión comunitaria que antes tenían.

Las fronteras en algún momento fueron superadas por ciertas complicidades entre fuerzas del Estado y grupos paramilitares. Varios de los pobladores entrevistados durante el trabajo de campo de este proyecto manifestaron que el Ejército Nacional actuaba conjuntamente con los paramilitares para combatir a la guerrilla; además, les permitían el transporte de insumos para la producción de pasta de coca.

En municipios como Samaná y corregimientos como Arboleda, del municipio de Pensilvania, el $100 \%$ de sus pobladores son víctimas del conflicto armado, por una u otra situación que tuvieron que atravesar, lo que ha impuesto un gran reto para el Estado y sus instituciones, que no siempre están preparadas para planear y atender a la población víctima. Samaná y Pensilvania encabezan la lista de los municipios con mayor índice de desplazamiento en Caldas, y también sobresalen en las estadísticas nacionales.

Muchos jóvenes abandonaron sus pueblos por temor a ser reclutados por uno u otro grupo; incluso si eran reclutados por el ejército o la policía, su familia era hostigada en las zonas de presencia guerrillera. Sin embargo, para muchos niños y jóvenes del Oriente de Caldas, el hacer parte de un grupo armado se convirtió en un proyecto de vida o en un modelo a seguir, lo que se reflejaba en sus prácticas y juegos del día a día, según lo expresado por varias de las maestras de escuelas y colegios de la región. El arma genera cierta sensación de poder, y esto era inspirador para quienes estaban en la búsqueda de territarias 42 
un referente identitario, sin pensar en las consecuencias violentas que traía portarla y usarla.

A pesar de estos múltiples efectos negativos, el conflicto armado permitió que al menos tres asuntos posteriores incidieran positivamente en la región: se puso en evidencia la presencia diferenciada del Estado (González \& Otero, 2006), que propició el caldo de cultivo necesario para la llegada y permanencia de los grupos armados, lo que llevó a las instituciones — públicas, privadas y de cooperación internacional-a pensar cómo llegar a los territorios. También, las y los pobladores de la región ganaron conciencia alrededor de las complicidades creadas entre algunos grupos ilegales y las administraciones municipales, develando redes clientelares que favorecieron la guerra. Finalmente, otro efecto tiene que ver con la llegada de la academia a estos territorios, con su papel de central de construir conocimiento profundo y comprometido que pueda traducirse en acciones concretas individuales, comunitarias e institucionales.

\section{Territorios en conflicto político: sujetos que encarnan las luchas por el poder}

Los territorios en conflicto político aquí son entendidos como luchas que se configuran entre sectores de la población, instituciones y/o partidos políticos que poseen significados opuestos frente al tersitorias 42 uso y la distribución de las fuentes y los dispositivos de poder en determinados espacios. Según los relatos de algunos pobladores del Oriente de Caldas, el conflicto político tiene un carácter problemático en esta región desde hace décadas, y este tipo de confrontaciones por el manejo de las administraciones públicas municipales terminan permeando y exacerbando los conflictos de tipo económico, ambiental, armado y cultural, por lo que ocupa un lugar central en el espacio social de las comunidades.

Como respuesta paliativa a los desastres vividos, el gobierno de Juan Manuel Santos creó e implementó una serie de programas institucionales dirigidos al apoyo a los sobrevivientes del conflicto armado. Si bien no se puede desconocer que estos recursos han ayudado especialmente al retorno de algunas familias desplazadas, y a generar cierta confianza en las instituciones del Estado, también han creado dependencia de los pobladores hacia esas instituciones, fortaleciendo el carácter paternalista del Estado y legitimando a los políticos que manipulan estos recursos. Es un efecto positivo y adverso de este conflicto.

En el proceso de transformación de los grupos paramilitares, y aprovechando el esquema clientelar del sistema político local y regional, a mediados de la década de los noventa se iniciaron alianzas con los políticos y se dieron los primeros casos de cooptación de la institucionalidad por parte de actores armados, con el posicionamiento del Movimiento del Pueblo, 
que integró los intereses de políticos y de paramilitares para "tomarse" las alcaldías en la región, en particular en el municipio de La Dorada. ${ }^{6}$ Con la expansión paramilitar y la aparición de nuevos partidos políticos en 2002 , la competencia de esas nuevas fuerzas con la tradicional coalición Barco-Yepista (partido liberal y conservador) llevó a nuevas coaliciones con grupos armados ilegales y a la captura de la institucionalidad (López-Hernández, s.d.,).

Desde la década del noventa, los políticos de varios municipios, entre ellos los de La Dorada, legitimaron el paramilitarismo como un actor político válido. Su presencia les proporcionó seguridad, un auge económico nunca antes visto y administración eficaz de "justicia” en la comunidad, yuxtaponiéndose un orden socioespacial de facto al orden legal, situación apreciada por muchos de los pobladores y funcionarios públicos.

De lo anterior surge la pregunta sobre la génesis del paramilitarismo en la región: ¿Los ejércitos paramilitares surgieron de respuestas colectivas de campesinos y hacendados para defender su propiedad y su patrimonio del accionar guerrillero?, $\mathrm{o}$ ¿fueron grupos armados creados por las élites regionales para apropiarse política y económicamente del territorio? Claramente esto da cuenta del surgimiento de un territorio en conflicto político en la medida que a las fuentes y a los dispositivos del poder se les otorga a una fuerza armada ilegal para que ejerza jurisdicción sobre el territorio municipal, con lo que se crea, en la práctica, un orden socioespacial de facto, o un territorio de desorden político.

Unos de los efectos generadores o positivos de este conflicto tiene que ver con la posibilidad de evidenciar que el poder, desde la mirada foucaultiana, es una fuerza dinámica y móvil que circula por el campo social. En un momento el ejercicio del poder se concentró en grupos armados ilegales y élites políticas que actuaban en conjunto, pero durante la última década han emergido múltiples organizaciones sociales que buscan disputárselo. Hay una mayor conciencia frente al ser sujetos políticos que pueden plantear sus desacuerdos e incluso ocupar cargos públicos. Un ejemplo de ello son las Agendas Ciudadanas, un proyecto que busca que las propuestas de base lleguen a los planes de desarrollo de quienes ocupen las alcaldías municipales. Se ha pasado de una presencia pasiva en el territorio, a una ciudadanía activa que se hace visible, que es crítica y propositiva en distintos momentos.

\section{Territorios en conflicto económico: la eterna batalla de producir para vivir}

Esta tipología la asumimos como la confrontación que se genera en el territorio entre sujetos, empresas o instituciones al momento de producir bienes y servicios o controlar la generación de recursos monetarios a partir de cierta actividad legal o ilegal. Los conflictos económicos se crean
${ }^{6}$ A continuación, se relacionan los casos de politicos de La Dorada investigados o condenados por nexos con grupos paramilitares. Nicolás Gómez, alcalde electo de La Dorada, 1994: condenado. Jaime Gutiérrez Ángel, alcalde de La Dorada, en 2003, por el Nuevo Partido: investigado-recluido. César Arturo Alzate, exalcalde de La Dorada, promotor del Movimiento del Pueblo y lider del Nuevo Partido en La Dorada: investigado-recluido. Justo Capera, alcalde de La Dorada, 2007, partido Liberal: investigadorecluido. Maribel Galvis, integrante del bloque Magdalena medio, concejal electa en La Dorada, 2000, por Actitud Renovadora: desmovilizada, prófuga (López-Hernández, s.d., pp. 96-103).

territarias 42




cuando hay una disputa por los recursos en un territorio, o cuando precisamente por la falta de posibilidades de generar ingresos se acude a vías ilegales para mejorar la economía, o se produce un desplazamiento económico para buscar mejores condiciones de vida en otros territorios.

El centro del conflicto es la disputa por los modelos de desarrollo en el que los territorios están marcados por la exclusión de las políticas neoliberales, productoras de desigualdades, amenazando la consolidación de la democracia (Mançano, 2009), y esto es evidente con la llegada de empresas y multinacionales a la zona de estudio, que acaban con sus bienes naturales, es decir, con sus posibilidades laborales que se han centrado históricamente en el sector agropecuario, generando desplazamientos económicos, o expulsiones, en términos de Sassen (2015). Además, en este tipo de zonas, donde muchos de los municipios aún viven bajo una lógica rural tradicional de producir para el mercado local o regional, contar con condiciones dignas de vida a partir del trabajo de la tierra resulta complejo. Las dificultades para la comercialización de los productos son grandes, $\mathrm{y}$ ello deriva en la "trampa de la intermediación", mediante la cual los transportadores y comerciantes intermediarios se quedan con la mayor parte de la renta que dejan los productos agropecuarios.

Las empresas llegaron a construir represas, trasvases e hidroeléctricas, para lo cual fue necesario tener mano de obra local. En un principio, esto resultó positivo para las comunidades, pues vieron allí una oportunidad laboral importante para su subsistencia:

La cosa mejoró mucho cuando se empezó a construir la Central Hidroeléctrica Miel I y cuando se empieza a construir también el Trasvase de Río Manso porque Isagén llega con una base militar más o menos grande, entonces eso de alguna manera generaba un tanto de seguridad en la zona y eso también dio fuentes de empleo, donde habían obreros que se ganaban hasta millón y medio por trabajar como obrero en la construcción, entonces eso cambió la dinámica (V. Bedoya, comunicación personal, 21 de mayo de 2015).

Más tarde, cuando terminaron las obras, quedó gran parte de la población desempleada y sin otros medios de subsistencia, por lo que los programas institucionales para las víctimas, tercera edad o familias aparecieron como una esperanza para satisfacer las necesidades básicas.

La siembra de cultivos de uso ilícito también generó conflictos económicos en la zona. La presión para acceder a esta opción económica la ejercieron ambos grupos (guerrilla y paramilitares), pues era una de sus principales fuentes de financiamiento; ambos bandos se disputaban los territorios para transformar los espacios productivos en zonas para el cultivo ilícito. La pugna se centraba en las tierras cultivables, la mano de obra campesina para cultivar, y el costo de la "protección" de 
la Policía y el Ejército para poder producir y comercializar cocaína (esta estrategia fue especialmente paramilitar).

La economía y los espacios productivos se transformaron durante la época del conflicto armado, atrayendo recursos numerosos pero de corta duración que exponían a los pobladores a dos situaciones en el futuro: verse enfrentados a la justicia por cultivar plantas consideradas ilícitas con el auspicio de la guerrilla o el ejército, o verse en crisis económica después de que llegaran los programas de erradicación manual y fumigación aérea (que también arrasó con otros cultivos legales), pues la rentabilidad de la coca no es la misma del café, el plátano o el maíz. Ambas situaciones se hicieron realidad en el Oriente de Caldas, más la segunda que la primera, lo que forzó a los campesinos a transformar nuevamente sus espacios productivos.

La presencia diferenciada del Estado, junto con la labor indeseable de los intermediarios, son algunos de los causantes de los conflictos económicos en el oriente caldense en la actualidad. Esto sumado a la labor que hoy desempeñan los prestamistas clandestinos o "gota a gota", que ofrecen dinero con altos intereses y utilizan formas violentas de cobranza. El territorio en conflicto económico se construye basado en las contradicciones ya señaladas, además de las dificultades para comercializar los productos y la deficiencia en las vías; no obstante, la resistencia y las luchas continúan, pues de ello depende la supervivencia de las familias, en las cuales los jóvenes ya están desplazándose hacia las ciudades en busca de mejores oportunidades, pues el campo ya no es un proyecto de vida viable, y no existe el mismo sentido de pertenencia hacia la tierra que se evidenciaba en generaciones anteriores. Se avecina entonces un nuevo ingrediente que transformará el territorio en conflicto económico: la supervivencia del campo y sus actividades agrícolas por falta de relevo generacional.

A partir de las crisis, nacieron dos alternativas para afrontar los efectos adversos de este conflicto: por un lado, los fondos rotatorios de economía solidaria, apoyados especialmente por el Programa de Desarrollo para la Paz del Magdalena Centro:

Surgen como una respuesta a las necesidades de un sector de la población colombiana caracterizado por tener ingresos económicos inestables, su vulnerabilidad social o ser víctima del conflicto armado, cuyos integrantes no tienen la posibilidad de acceder a servicios bancarios (Bedoya, 2017, p. 118).

Son una forma de cooperar para subsistir que, mientras satisface las necesidades básicas de las familias y comunidades, también fortalece el tejido social. En segundo lugar, los mercados campesinos y agroecológicos han aparecido como opción para eliminar los intermediarios, producir de forma más consciente y saludable y apostarle a la justicia comunitaria y ecológica. 
7 Proyecto Hidroeléctrico Agua Bonita, PAUJIL II, Esmeralda, Palenque, Santo Domingo, Pantágoras, Manzanares, Marquetalia (OCA, 2016).

\section{tersitarias 42}

La Universidad de Caldas ha apoyado este proceso.

\section{Territorios en conflicto ambiental: la naturaleza como bien a preservar o como recurso a explotar}

Los conflictos ambientales son disputas que se producen entre sujetos, empresas y/o instituciones que poseen concepciones opuestas frente a la forma de relación con la naturaleza, su apropiación, transformación o preservación. La llegada de proyectos hidroeléctricos al Oriente de Caldas es hoy uno de los principales generadores de conflictos en la zona, a tal punto de considerarse que los conflictos ambientales llegaron a remplazar al conflicto armado, y algunas empresas apoyadas en instrumentos legales se dedican a la explotación desmedida de los bienes naturales del territorio, afectando el espacio físico y a quienes lo habitan.

De acuerdo con el documento publicado por el Observatorio de Conflictos Ambientales (OCA) de la Universidad de Caldas (2016), El Proyecto Hidroeléctrico La Miel I pertenece a Isagén, empresa nacional que fue vendida en un $76.9 \%$ al fondo de inversión canadiense Brookfield Asset Management en enero de 2016, y ha afectado a los municipios de Norcasia, Samaná, Pensilvania, Marquetalia, Manzanares, Victoria y La Dorada.

Los bienes naturales por excelencia, suelo y agua, son objeto de relaciones de poder y están en el corazón de múltiples estrategias; también están integrados a técnicas que permanentemente están en evolución. Las técnicas de utilización del suelo y del agua no dejan de ser perfeccionadas. A continuación, se cita un relato que da cuenta de los efectos de la concentración del poder en pocas manos en el uso de los recursos:

[Refiriéndose a un relato de miembros de una organización de pescadores] [...] nos contaba en el tiempo de subienda, que hoy en día eso no se ve, cómo era. Entonces nos dimos cuenta, ese día que nosotras hicimos el recorrido, se miraba como subía el nivel del agua, pues, estaban generando [energía], y luego bajaban, era algo como muy drástico, es decir, el río crecía y luego otra vez bajaba, así como rápido, entonces eso ¿qué generaba? erosiones en las orillas del río, que se llevaba parte de las tierras y los pescados aparecían como muertos o con enfermedades. Entonces Isagén llevó biólogos a hacer estudios, pero obviamente toda la información que recogen no se la van a decir a la comunidad ('Camila', comunicación personal, 23 de mayo de 2015).

El Proyecto Eléctrico Guarinó, de la misma multinacional, generó distintas movilizaciones y acciones jurídicas que articularon a la ciudadanía, organizaciones sociales e instituciones para impedir la construcción y puesta en marcha del proyecto, pero no logró detenerse. Hay ocho proyectos hidroeléctricos ${ }^{7}$ que están en fase de estudio de diagnóstico ambiental 
de alternativas según el OCA (2016), lo que demuestra el interés que tienen las empresas por explotar un territorio tan rico en bienes naturales como el Oriente de Caldas.

El desplazamiento ambiental es uno de esos impactos que, a raíz de las transformaciones territoriales, obliga a los pobladores a abandonar sus tierras, pues los bienes naturales ya no alcanzan a satisfacer sus necesidades, ya sea porque se han reducido considerablemente o porque han desaparecido. El desplazamiento ambiental según Aguirre, Álvarez, Arango, Díaz, García, García, et al. (2014):

"Se refiere al desplazamiento humano provocado por razones asociadas a eventos hidrometereológicos, variabilidad climática, degradación ambiental, escases o pérdida de recursos naturales, intervención estatal en zonas convertidas en territorios de riesgo (Kälin, 2008) o efectos antrópicos en el territorio, derivados del desarrollo de megaproyectos mineros o de infraestructura, todo lo cual, en un espectro amplio, tiene relación con el cambio climático" (pp. 48-29).

La intervención estatal en zonas de riesgo y los efectos antrópicos en el territorio que generan el desarrollo de megaproyectos son las dos principales causas del desplazamiento ambiental en el Oriente de Caldas, lo que quiere decir que el cambio climático en este territorio se debe más a procesos antropogénicos que naturales. El concepto de desplazamiento ambiental seguramente tomará más fuerza en el país a raíz del proceso de construcción de paz que se está atravesando, pues hasta ahora ha sido el desplazamiento forzado, generado por el conflicto armado, el que ha tenido mayor protagonismo.

La concentración de tierras en pocas manos es otra de las situaciones que genera conflictos ambientales, y en Pensilvania es uno de los temas recurrentes, pues el monocultivo, que es uno de los usos que le dan al suelo los grandes terratenientes, es causa de cambios climáticos y de posibles desplazamientos ambientales (reemplazan la vegetación nativa por especies maderables como el pino), lo que ha cambiado significativamente el clima, afectando los cultivos de las fincas vecinas en una gran extensión.

Los conflictos ambientales, sin embargo, trajeron consigo una toma de consciencia frente a la necesidad de preservar los bienes naturales, como el agua y la tierra, lo que ha llevado a las y los pobladores a asumir una posición más crítica y menos idealizante frente al papel de las multinacionales y grandes empresas que suelen otorgar beneficios temporales en los territorios y daños ecológicos difíciles de subsanar a largo plazo.

\section{Territorios en conflicto cultural: la fragmentación del yo y del nosotros}

El conflicto cultural es comprendido aquí como un choque que se genera entre territarias 42 17 
sujetos y/o comunidades cuando la conducta del otro se percibe como una amenaza para la identidad o los esquemas de pensamiento y acción propios. Este claramente se vio potenciado con el conflicto armado, sin negar que hay otros factores que lo activan, pero gran parte de las situaciones de fragmentación de las relaciones de vecindad, la ruptura del sentido de cooperación y el deterioro de la confianza entre las personas de la comunidad abrieron unas heridas tan profundas y más difíciles de sanar que las producidas por las balas. Para reafirmar el presupuesto recurrimos a Harvey (1977) quien plantea que:

El espacio solo adquiere un significado en función de las relaciones significativas, y una relación significativa no puede ser entendida al margen del estado cognoscitivo de los individuos ni del contexto dentro del cual se encuentran, y por consiguiente, el espacio social [...] está compuesto por un conjunto de sentimientos, imágenes y reacciones con respecto al simbolismo espacial que rodea al individuo (p. 28).

Testimonios de los pobladores relataban cómo las conversaciones con los vecinos y los conocidos del pueblo adquirieron un tono "neutro", evitando decir lo que realmente se pensaba; no se sabía "en qué andaba" la otra persona, solo se hablaba con la pareja, en la intimidad de la cama territarias 42 18 y en voz baja sobre los sentimientos que generaba el conflicto.
En el caso del desplazamiento forzado provocado por la acción de los grupos armados ilegales, cientos de personas llegaron a los centros urbanos de los municipios del Oriente de Caldas. La Dorada ha sido el municipio receptor más visible en esta zona, y la llegada de pobladores de otros territorios con otras costumbres, necesidades e identidades ha generado conflictos culturales que desequilibran la convivencia entre las y los ciudadanos.

Debido al sentimiento de pertenencia a un territorio, la llegada de personas desplazadas genera cierta incertidumbre y malestar, por cuanto muchas personas de la comunidad receptora consideran que los programas estatales deben ser otorgados solamente a la población nativa, pero esto no sucede por la condición de vulnerabilidad en la que se encuentran las personas desplazadas, que hace que tengan prioridad para el acceso a los programas.

En ocasiones, los programas institucionales son planeados y diseñados desde el nivel central, sin procesos investigativos o diagnósticos suficientes de las realidades locales, lo que va configurando una visión asistencialista de los mismos que producen conflictos culturales entre recién llegados y nativos de los territorios, pues se dan distribuciones desiguales de los recursos sin una debida socialización o explicación de la situación.

En las regiones afectadas por el conflicto se ha venido presentando una situación particular de ver al Estado como aquel que debe suplir todas las necesidades de 
las comunidades, posiblemente porque los pobladores han tenido que soportar el abandono estatal durante décadas. Sin embargo, esta perspectiva ha devenido en la pérdida de autonomía de los sujetos, así como en la desmotivación para organizarse, que, aunque no es generalizada, sí es notable en las conversaciones cotidianas.

A raíz del conflicto armado se han transformado dos aspectos culturales vitales: las interacciones entre pobladores y la visión del territorio. En el primer aspecto, hubo situaciones donde los grupos armados desautorizaban a distintos actores que antes eran respetados en los territorios, y esta visión del actor armado como única autoridad quedó plasmada en la mente de quienes vivieron la guerra en su cotidianidad. Por otro lado, la estigmatización ha sido otro tema generador de conflictos culturales, pues entre los mismos pobladores de los territorios comenzaron los señalamientos hacia quienes habitaban lugares dominados por la guerrilla o los paramilitares, dificultando la convivencia e interacción otrora pacífica entre las personas.

El hecho de verse obligado a acatar una orden o hacer un favor a un actor armado, ya era una razón para ser estigmatizado. Se generaron estigmas sociales entre los sujetos, y también territoriales, pues comenzaron a subvalorarse los espacios alguna vez ocupados por actores armados, y a construirse fronteras invisibles entre los territorios: para los de arriba, abajo están los 'paracos' y, para los de abajo, arriba los 'guerrillos'.
Cuando se territorializa el estigma, sus habitantes también los interiorizan y reproducen al momento de configurar su identidad, aunque no de forma homogénea; hay nuevas fronteras que fragmentan el territorio, el espacio conocido se vuelve hostil, y las relaciones más cotidianas entre amigos o parejas comienzan a desestabilizarse. Los estigmas territoriales, al igual que los demás conflictos culturales que se han explicado en este apartado, dan cuenta de una fragmentación del tejido social en el Oriente de Caldas que es importante atender pronto, y que no solo se generó a partir de la llegada de los grupos armados ilegales, sino también por la presencia diferenciada del Estado.

Por otro lado, la dimensión intrapersonal también se ha afectado con los conflictos culturales, especialmente en dos aspectos: el proyecto de vida y las emociones. En el primer aspecto es notable que culturalmente el hacerse poseedor de un arma y miembro de un grupo armado terminó imponiéndose como el modelo para los niños y jóvenes de los territorios, lo que generó una desmotivación por la educación y por un proyecto de vida en el campo. A este fenómeno podría llamársele "la conquista de los deseos", pues la imitación de lo militar opera a partir de la seducción de la subjetividad.

Con respecto a la territorialización de las emociones, que es otro de los aspectos de la dimensión intrapersonal de los conflictos culturales, que a su vez se entrecruza con lo interpersonal, vale la pena 
resaltar que el miedo, la vergüenza y la humillación fueron las más recurrentes en los relatos de las y los pobladores de la zona (Gómez \& Moreno, 2016), lo que dejó unas secuelas psicológicas imborrables en los actores sociales, pues por ejemplo, cuando llega una persona de otro municipio a algún espacio que vivió el conflicto armado, se encienden las alarmas en la población, pues hay una tendencia naturalizada a desconfiar de los foráneos y mirarlos como extraños.

A pesar de lo anterior, se generó una consecuencia positiva que ha beneficiado al Oriente de Caldas: desde inicios de la década de los 2000 han llegado instituciones como el Programa de Desarrollo para la Paz del Magdalena Centro, la Deutsche Gesellschaft für Internationale Zusammenarbeit (GIZ), la Fundación Apoyar, los programas de responsabilidad empresarial de La Chec, distintas universidades del Eje Cafetero y del resto del país, entre otras, que han trabajado arduamente en la reconstrucción del tejido social, la formación política y el potencial organizativo de las y los pobladores. Actualmente, se desarrollan múltiples acciones pedagógicas en las que se comunica que el otro no es una amenaza, sino que puede ser un aliado al momento de enfrentar los conflictos intra e interpersonales de forma no violenta.

La nueva configuración regional, conocida hoy como Magdalena Centro, ha sido también una posibilidad no solo de reordenamiento territorial, sino también de incidencia cultural para resignificar el estigma.

\section{Conclusiones}

Durante décadas se ha pensado que el conflicto social es únicamente negativo y destructor de lo positivo en los territorios; sin embargo, a partir de este proceso investigativo, y basados también en otras perspectivas del conflicto social, se infiere que las dinámicas conflictivas son inherentes a la vida social y representan un motor de cambio que potencia la creatividad de quienes las enfrentan, moviliza a las instituciones y activa la resiliencia en momentos de crisis, lo que puede evidenciarse en los nuevos sujetos políticos que aparecen, la exigencia de una mayor presencia del Estado, las alternativas económicas solidarias y campesinas, las acciones de defensa de los bienes naturales, las iniciativas pedagógicas para la transformación cultural, entre otros efectos generadores.

El conflicto produce nuevos territorios, como bien pudo evidenciarse en la tipología propuesta, es decir, el conflicto social ha transformado lo que geográficamente conocemos como el Oriente de Caldas, pero esto no quiere decir que no haya hoy distintas resistencias y agenciamientos comunitarios e institucionales para la construcción de paz dirigidos a restablecer las relaciones comunales afectadas, pues los procesos de territorialización son dinámicos, constantes y están en permanente transformación y disputa. 
Los distintos conflictos que se han configurado en el territorio han provocado una desconfianza generalizada hacia las instituciones del Estado, por su presencia intermitente y en ocasiones corrupta. Sin embargo, el diseño y ejecución de más de veinte programas para la atención de las víctimas y de la población vulnerable, la llegada de instituciones públicas y privadas, la emergencia de múltiples organizaciones sociales, así como la inclusión en los planes de desarrollo municipales de algunas de las propuestas que construye la sociedad civil organizada, permiten que hoy se esté recuperando lentamente la confianza.

Si bien los actores armados legales e ilegales impusieron distintas lógicas de desterritorialización física, simbólica y emocional, las y los pobladores de los municipios del Oriente de Caldas han desplegado también sus estrategias de reterritorialización, donde comienzan a aparecer nuevos significados funcionales y simbólicos de sus espacios vitales.

La utilización de las tipologías como recurso metodológico permitió reconocer y visibilizar la multiterritorialidad que hoy caracteriza al Oriente de Caldas, donde se evidencian múltiples conflictos que transforman el espacio, así como diversos actores sociales e institucionales que interactúan y se confrontan constantemente con miras a disputarse los significados sobre el uso, gestión y apropiación de este.

Derivado de su carácter relacional, el conflicto social es esencialmente inestable, de ahí deriva su potencial para cambiar y transformar el orden socioespacial vigente; por lo tanto, no se puede desconocer que el conflicto social produce permanentemente fricciones, puesto que todo territorio es producto de tensiones y negociaciones entre sus actores sociales, de las cuales se derivan nuevos posicionamientos en el espacio social y por ende surgen o se redistribuyen capacidades para conservar o transformar el territorio. El sentido creativo o destructivo de los cambios está asociado, tanto con la génesis o historia de la región en particular, sin desconocer su imbricación con los ámbitos nacional e internacional, como con las condiciones objetivas del presente. Por lo anterior, no es posible acceder a soluciones fáciles y espontáneas a problemas sociales complejos y de vieja data de una región.

\section{Referencias}

Aguirre, A., Álvarez, J., Arango, B., Díaz, C., García, C., García, D., ... Valencia, J. (2014). Cambio Climático y Desplazamiento Ambiental Forzado: Estudio de Caso en la Ecorregión Eje Cafetero en Colombia. Armenia: Universidad La Gran Colombia.

Bedoya, V. (2017). Los fondos rotatorios de economía solidaria como estrategia de movilización social para la construcción de paz en la región del Magdalena Centro. Revista Eleuthera, (17), 110-126. territarias 42

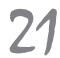


Franco, V. (2009). Orden contrainsurgente ydominación. Bogotá, D.C.: Siglo del Hombre Editores - Instituto Popular de Capacitación.

Gómez, A. \& Moreno, M. (2016). Territorializaciones del conflicto y geosímbolos de las emociones en el Magdalena Centro (Colombia). Argumentos, 29(81), 203-217.

González, F. \& Otero, S. (2006). La presencia diferenciada del Estado: un desafio a los conceptos de gobernabilidad y gobernanza. Cuaderno Usos y desafíos del concepto de gobernanza en Colombia. Recuperado de: http://www.institutgouvernance.org/es/analyse/ficheanalyse-237.html

Grimson, A. (2003). Los procesos de fronterización: flujos, redes e historicidad. En C. I. García (comp.), Fronteras, territorios y metáfora (pp. 5-34). Medellín: Hombre Nuevo Editores.

Haesbaert, R. (2004). Dos múltiplos territórios á multiterritorialidade. Recuperado de http://www.ufrgs. br/petgea/Artigo/rh.pdf

Haesbaert, R. (2011). El mito de la desterritorialización. Del fin de los territorios a la multiterritorialidad. México, D.F.: Siglo XXI Editores.

Harvey, D. (1977). Urbanismo y desigualdad social. Madrid: Siglo XXI Editores.

Instituto Geográfico Agustín Codazzi (IGAC). (2012). Atlas sobre la Distribución de la Tierra en Colombia. Bogotá: Centro
Kalyvas, S. (2004). La ontología de la "violencia política": acción e identidad en las guerras civiles. Análisis Político(52), 51-76.

López-Hernández, C. (s.d.). Monografía político electoral del Departamento de Caldas 1997-2007. Bogotá: Misión de Observación Electoral - Corporación Nuevo Arcoiris.. Recuperado de http://moe.org.co/home/doc/ moe_mre/CD/PDF/caldas.pdf

Luhmann, N. (1995). Poder. México, D.F.: Editorial Anthropos.

Mançano, B. (2009). Sobre a tipología de territórios. En M. Saquet (Ed.) Territórios e territorialidades (pp. 197215). São Paulo: Expressão Popular.

Mançano, B. (2013). Territorios: teoría y disputas por el desarrollo rural. Recuperado de http://www.cedem. uh.cu/revista

Massey, D. (2008). Ciudad Mundial. Caracas: Ediciones el perro y la rana.

Monnet, J. (1999). Globalización y territorializaciones 'areolar' $y$ 'reticular': Los casos de Los Ángeles y la Ciudad de México. En V Seminario Internacional de la Red Iberoamericana de Investigadores sobre Globalización y Territorio. Universidad Autónoma del Estado de México, Toluca.

Montañez, G. \& Delgado, O. (1998). Espacio, territorio y región: conceptos básicos para un proyecto nacional. Revista del Departamento de Geografía de la Universidad Nacional de Colombia, VII(1-2), 120-134. 
Nates, B. (2011). La territorialización del conocimiento. Categorias y clasificaciones culturales como ejercicios antropológicos. Barcelona: Anthropos

Nates, B. (2011b). Soportes teóricos y etnográficos sobre conceptos de territorio. Co-Herencia, 8(14), 209-229.

Observatorio de Conflictos Ambientales (OCA) (2016). Estado del sector hidroeléctrico y su viabilidad por el sector politico-gubernamental; Minambiente, ANLA, Corpocaldas, Gobernación, Inficaldas; Empresas privadas, mixtas y su no viabilidad ambiental por parte de las comunidades afectadas en el Departamento de Caldas. Manizales: Universidad de Caldas.

Raffestin, C. (2011). Por una geografía del poder. Michoacán: El Colegio de Michoacán.

Sassen, S. (2015). Expulsiones. Brutalidad y complejidad en la economía global. Buenos Aires: Editorial KATZ.

Simmel G. (2010). El Conflicto, sociología del antagonismo. Madrid: Ediciones Sequitur.

Weber, M. (2002). Economia y sociedad. Esbozo de sociología comprensiva. Madrid: Fondo de Cultura Económica. 